\title{
Changes in plastochromanol-8 and tocopherols during germination in Ethiopian mustard lines with contrasting tocopherol levels
}

\author{
Elena García-Navarro, Begoña Pérez-Vich and Leonardo Velasco* \\ Instituto de Agricultura Sostenible (IAS-CSIC), Alameda del Obispo s/n 14004, Córdoba, Spain
}

(Received 20 July 2013; accepted after revision 3 March 2014; first published online 11 April 2014)

\begin{abstract}
Plastochromanol-8 and tocopherols are natural antioxidants with vitamin $\mathrm{E}$ activity that protect seeds and plants from oxidative damage. Whereas $\alpha$-tocopherol is predominant in photosynthetic tissues, $\gamma$-tocopherol is more abundant in seeds. Ethiopian mustard (Brassica carinata A. Braun) seeds contain varying levels of both tocopherol forms. The objective of this research was to study changes in plastochromanol-8 and tocopherol contents during seed germination in Ethiopian mustard lines with contrasting seed tocopherol levels, and to evaluate their influence on seed germination and seedling growth. Cotyledons and radicles of seven lines with contrasting seed tocopherol levels and a control line were sampled periodically until $120 \mathrm{~h}$ after sowing (HAS) under light and dark conditions, and were analysed for plastochromanol-8 and tocopherol contents. The main factors genotype, tissue, light and HAS were significant for all the traits, excepting the light effect for total tocopherol content. Most of the lines showed a gradual decrease in $\gamma$-tocopherol that was nearly completely replaced by $\alpha$-tocopherol at $120 \mathrm{HAS}$. However, line BCT-4, with high $\gamma$-tocopherol content in seeds, exhibited unusually high $\gamma$-tocopherol content in cotyledons and radicles during the whole sampling period. Light treatment and initial seed tocopherol levels had no influence on germination percentage. Despite significant differences for seedling development among genotypes, no clear association between seedling development and seed tocopherols was observed. The results revealed that the unusual presence of high $\gamma$-tocopherol levels in cotyledons and radicles of line BCT- 4 did not have an effect on seedling growth.
\end{abstract}

*Correspondence

Email: lvelasco@ias.csic.es
Keywords: $\alpha$-tocopherol, Brassica carinata, Ethiopian mustard, $\gamma$-tocopherol, plastochromanol-8, seed germination, tocopherols

\section{Introduction}

Tocopherols (vitamin E) are powerful lipid-soluble antioxidants synthesized by photosynthetic organisms, including plants and some algae and cyanobacteria. They are composed of a polar chromanol group and a phytyl-derived side chain. There are four forms of tocopherols, named $\alpha, \beta, \gamma$ and $\delta$, which differ by the number and position of methyl groups in the polar moiety (Mène-Saffrané and DellaPenna, 2010). Tocopherols are ubiquitously distributed in plants. In general, $\alpha$-tocopherol is the most common tocopherol form in photosynthetic tissues, such as leaves, whereas $\gamma$-tocopherol is most abundant in other plant parts, such as dicot seeds, fruits and tubers (Horvath et al., 2006). Seeds accumulate 10-20 times more tocopherols than leaves (Mène-Saffrané and DellaPenna, 2010). As in vivo antioxidants, tocopherols play a crucial role in scavenging reactive oxygen species and lipidsoluble by-products of oxidative stress (Munné-Bosch and Alegre, 2002). At the plant level, tocopherols protect plants from a number of environmental stresses (Munné-Bosch, 2005; Kumar et al., 2013). In seeds, tocopherols protect against non-enzymatic lipid oxidation during storage, germination and early seedling development (Sattler et al., 2004). Tocopherols also play a major role in human nutrition due to their vitamin $\mathrm{E}$ activity and subsequent health-enhancing properties (Packer and Obermüller-Jevic, 2002) as well as in vitro natural antioxidants of vegetable oils (Kamal-Eldin, 2006).

Ethiopian mustard (Brassica carinata A. Braun) is an oilseed crop closely related to rapeseed/canola (Brassica napus L.). Like other Brassica spp., Ethiopian mustard seeds contain varying proportions of $\alpha$ - and $\gamma$-tocopherol (Goffman et al., 1998). They also contain 
small amounts of plastochromanol-8, a compound with similar structure and function as tocopherols (Mène-Saffrané et al., 2010). Studies in several species of the Brassicaceae have shown that $\alpha$-tocopherol content increases during the initial steps of seedling development (Zielinski and Kozlowska, 2003; Zhang et al., 2007). However, no consistent changes in $\gamma$-tocopherol content have been reported. Whereas in some cases $\gamma$-tocopherol content was found to increase during the first 3-4d after sowing (DAS) to decrease afterwards, in other cases $\gamma$-tocopherol content decreased gradually from a maximum content in dry seeds (Zielinski and Kozlowska, 2003; Zhang et al., 2007). Such differences have been observed between species and also within species, though information about intraspecific variation for tocopherol changes during germination is scarce. In rapeseed seedlings, Zhang et al. (2007) reported a marked gradual reduction of $\gamma$-tocopherol after germination, while Zielinski and Kozlowska (2003) found a different pattern in which $\gamma$-tocopherol content increased initially and then decreased. In both studies, changes in tocopherols during germination were influenced by the presence or absence of light.

Recently, a set of Ethiopian mustard lines with contrasting levels of total seed tocopherol content, as well as different relative concentrations of $\alpha$ - and $\gamma$-tocopherol, was developed (Velasco et al., 2013). The availability of this plant material provided a unique opportunity for studying how changes in tocopherols during germination are related to the initial seed tocopherol levels, and the relationship of such changes with seedling growth. Accordingly, the objective of this research was to study changes in plastochromanol-8 and tocopherol contents during seed germination in Ethiopian mustard lines with contrasting seed tocopherol levels, and to evaluate their influence on seed germination and seedling growth.

\section{Materials and methods}

\section{Plant material}

Seven lines with contrasting levels of seed tocopherols were used. The lines had been developed in a selection programme reported by Velasco et al. (2013). Lines BCT-1 and BCT-2 had increased total tocopherol content, the latter also showing increased concentration of $\gamma$-tocopherol; BCT-3 had a reduced total tocopherol content and increased concentration of $\alpha$-tocopherol; BCT- 4 and BCT- 5 had increased concentration of $\gamma$-tocopherol; and BCT- 6 and BCT-7 had an increased concentration of $\alpha$-tocopherol. Line C-101 was used as a control. Increased or reduced levels of tocopherols in the seven lines were defined in relation to line C-101 in the selection programme (Velasco et al., 2013). Thousand-seed weight, plastochromanol-8 content, and tocopherol content and profile in the mature, dry seeds of the eight lines are shown in Table 1.

\section{Sampling}

Around 400 seeds of each line were placed on moistened filter paper in eight Petri dishes with around 50 seeds each, which were transferred to a growth chamber at $25 / 18^{\circ} \mathrm{C}$ (day/night) with a 16-h photoperiod, and photon flux density of $300 \mu \mathrm{mol} \mathrm{m}{ }^{-2} \mathrm{~s}^{-1}$. Half of the Petri dishes of each line were wrapped in two layers of aluminium foil to prevent light intrusion.

Seeds were sampled at 12, 24, 36, 48, 60, 72, 96 and $120 \mathrm{~h}$ after sowing (HAS), both under light and dark conditions. The percentage of germination was recorded at each sampling time. In this case, germinated seeds were counted in four Petri dishes per line and light treatment, which were considered replications. For analysis of plastochromanol-8 and tocopherols, three replicates per line and light treatment

Table 1. Thousand seed weight (TSW; g), plastochromanol-8 (Plasto-8) and total tocopherol (T) contents $\left[\mathrm{mg}(\mathrm{kg} \text { seeds })^{-1}\right]$, and concentration of individual tocopherols (\% total tocopherols) in the seeds of seven Ethiopian mustard lines with contrasting levels of tocopherols and control line C-101. The traits for which each line was selected are highlighted in bold ${ }^{\mathrm{a}}$

\begin{tabular}{lccccccc}
\hline Line & TSW & Plasto-8 & Total-T & $\alpha$-T & $\beta$-T & $\gamma$-T & $\delta$-T \\
\hline BCT-1 & $4.3 \pm 0.4$ & $1.6 \pm 0.1$ & $\mathbf{2 3 8} \pm \mathbf{6 . 7}$ & $51.9 \pm 12$ & $0.4 \pm 0.0$ & $45.3 \pm 1.1$ & $2.5 \pm 0.1$ \\
BCT-2 & $3.5 \pm 0.2$ & $1.5 \pm 0.2$ & $\mathbf{2 3 1} \pm \mathbf{5 . 6}$ & $22.8 \pm 1.9$ & $0.1 \pm 0.0$ & $\mathbf{7 3 . 8} \pm \mathbf{1 . 7}$ & $3.3 \pm 0.2$ \\
BCT-3 & $3.9 \pm 0.3$ & $1.7 \pm 0.1$ & $\mathbf{8 0} \pm \mathbf{2 . 5}$ & $\mathbf{6 6 . 1} \pm \mathbf{0 . 8}$ & $0.5 \pm 0.0$ & $31.2 \pm 0.8$ & $2.2 \pm 0.1$ \\
BCT-4 & $3.6 \pm 0.2$ & $1.9 \pm 0.2$ & $188 \pm 9.4$ & $22.6 \pm 1.4$ & $0.1 \pm 0.0$ & $\mathbf{7 4 . 2} \pm \mathbf{1 . 3}$ & $3.1 \pm 0.2$ \\
BCT-5 & $2.9 \pm 0.3$ & $1.2 \pm 0.1$ & $194 \pm 10.6$ & $17.5 \pm 1.4$ & $0.1 \pm 0.0$ & $\mathbf{7 9 . 2} \pm \mathbf{1 . 3}$ & $3.2 \pm 0.2$ \\
BCT-6 & $5.1 \pm 0.6$ & $1.4 \pm 0.0$ & $140 \pm 3.9$ & $\mathbf{6 5 . 9} \pm \mathbf{5 . 3}$ & $0.4 \pm 0.1$ & $32.2 \pm 5.2$ & $1.5 \pm 0.2$ \\
BCT-7 & $4.9 \pm 0.4$ & $1.4 \pm 0.1$ & $152 \pm 2.6$ & $\mathbf{6 9 . 4} \pm \mathbf{4 . 0}$ & $0.4 \pm 0.0$ & $28.9 \pm 3.7$ & $1.3 \pm 0.2$ \\
C-101 & $4.5 \pm 0.1$ & $1.2 \pm 0.1$ & $159 \pm 2.3$ & $49.0 \pm 4.6$ & $0.3 \pm 0.1$ & $48.1 \pm 4.6$ & $2.6 \pm 0.1$ \\
\hline
\end{tabular}

${ }^{\mathrm{a}}$ Data given as mean \pm standard error of the mean in the analysis of seeds from six individual plants per line. 
were used at each sampling time, each consisting of six seeds. Seeds of each replication were immediately divided into cotyledons and radicles, which were stored separately in Eppendorf tubes at $-80^{\circ} \mathrm{C}$. The seed coats were discarded. After lyophilization, tissues were weighed, ground to a fine powder with a glass rod, and analysed for tocopherol and plastochromanol8 contents as described below. No cotyledons and radicles were analysed at $0 \mathrm{HAS}$ due to the difficulty of removing seed coats from the dry seeds, which had average diameters between 1.4 and $2.2 \mathrm{~mm}$.

Alternatively, a second experiment was conducted to study differences in whole seeds between 0 and 12 HAS. Seeds of the eight lines were placed on moistened filter paper under light and dark conditions, as described above. After zero and 12 HAS, three replicates of six seeds per line were placed in Eppendorf tubes, stored at $-80^{\circ} \mathrm{C}$, lyophilized, ground and analysed for tocopherols and plastochromanol-8 contents.

The results from the germination experiment revealed large differences for the tocopherol profile in the cotyledons of line BCT-4, with high $\gamma$-tocopherol content in seeds, as compared with the other lines. To confirm whether the differences for the tocopherol profile were also observed in true leaves, 24 seeds of lines BCT-2, BCT-4 and BCT-5, with high $\gamma$-tocopherol content, and control line C-101 were germinated and planted into 3-litre pots. Three expanding leaves per plant were cut at $94 \mathrm{~d}$ after planting, lyophilized and ground. Ground tissue was used for tocopherol analyses.

\section{Analyses of tocopherols and plastochromanol-8}

Extraction of tocopherols and platochromanol-8 from ground tissue, separation by high-performance liquid chromatography (HPLC) and quantification were performed following the procedures described by Goffman et al. (1999) and Velasco and Goffman (2000), using a fluorescence detector Waters 474 (Waters, Milford, Massachusetts, USA) at $295 \mathrm{~nm}$ excitation and $330 \mathrm{~nm}$ emission and iso-octane/tert-butylmethylether (94:6) as eluent at an isocratic flow rate of $0.8 \mathrm{ml} \mathrm{min}^{-1}$. Chromatographic separation of the tocopherols was performed on a LiChrospher 100 diol column [250 $\mathrm{mm} \times 2 \mathrm{~mm}$ internal diameter (ID)] with $5-\mu \mathrm{m}$ spherical particles, connected to a silica guard column (LiChrospher Si 60, $5 \mathrm{~mm} \times 4 \mathrm{~mm}$ ID). Quantitative determination of tocopherols was performed using external calibration curves obtained for each of the tocopherol homologues $\alpha-, \beta-, \gamma$ - and $\delta$-tocopherol (Calbiochem Tocopherol Set, Cat. No. 613424, Merck KGaA, Darmstadt, Germany). Total tocopherol content was calculated as the sum of the four tocopherol forms, expressed as $\mathrm{mg}$ ( $\mathrm{kg}$ tissue $)^{-1}$. The tocopherol profile was expressed as the relative concentration of each tocopherol form in relation to the total tocopherol content (\% total tocopherols). Plastochromanol-8 was identified by comparison of the retention time of the peak with that of Linum spp. seed samples with known plastochromanol-8 content (Velasco and Goffman, 2000) at different flow rates. Plastochromanol-8 was quantified using the calibration curves developed for $\gamma$-tocopherol (Balz et al., 1993).

\section{Statistical analysis}

Data were analysed by the General Linear Model procedure of IBM SPSS Statistics version 19.0 (IBM Corp., Armonk, New York, USA) using a factorial model with four main fixed factors (genotype, light treatment, tissue and HAS) and their corresponding interactions in the experiment comparing 12 to 120 HAS, and three factors (genotype, light treatment and HAS) in the experiment comparing 0 and 12 HAS. The analysis of variance of factors influencing seed germination considered genotype, light treatment and HAS as main factors. Germination percentage was arcsine transformed. For the study of factors influencing seedling growth, analyses of variance were carried out separately for cotyledons and radicles, using genotype, light treatment and HAS as main factors. Comparison of means at a given sampling time was conducted by paired $t$-tests using the abovementioned statistical software. Pearson's correlation coefficients between thousand-seed weight and both cotyledon and radicle weight at 120 HAS were computed to evaluate the influence of seed weight, closely related to seed size, on seedling growth.

\section{Results \\ Factors influencing contents of plastochromanol-8 and tocopherols}

First, we investigated whether early imbibition (0 versus 12 HAS) affected the plastochromanol-8 and tocopherol contents in whole seeds. The analysis of variance showed significant differences between genotypes for plastochromanol-8 content, total tocopherol content and concentrations of individual tocopherols. Conversely, light, HAS and the interactions were not significant (Table 2). A second experiment investigated differences for tocopherol traits by analysing cotyledons and radicles separately from 12 to 120 HAS. The analysis of variance indicated that the effects of genotype, tissue and HAS were significant for all the traits (Table 3). The effect of light was significant for plastochromanol-8 content and concentrations of individual tocopherols, but not for total tocopherol content. Similarly, all the interactions 
Table 2. Analysis of variance ( $F$ values) for plastochromanol8 (Plasto-8) content $\left[\mathrm{mg}(\mathrm{kg} \text { dry tissue })^{-1}\right]$, total tocopherol (T) content $\left[\mathrm{mg}(\mathrm{kg} \text { dry tissue })^{-1}\right]$ and concentration of individual tocopherols (\% total tocopherols) in whole seeds of eight Ethiopian mustard lines during the first $12 \mathrm{~h}$ after sowing (HAS) under light and dark conditions

\begin{tabular}{lrrrrr}
\hline $\begin{array}{l}\text { Source of } \\
\text { variation }\end{array}$ & Plasto-8 & \multicolumn{1}{c}{ Total-T } & \multicolumn{1}{c}{$\alpha-\mathrm{T}$} & \multicolumn{1}{c}{$\gamma-\mathrm{T}$} & \multicolumn{1}{c}{$\delta-\mathrm{T}$} \\
\hline Genotype (G) & \multicolumn{1}{c}{$381.0^{* *}$} & $119.1^{* *}$ & $840.6^{* *}$ & $522.4^{* *}$ & $351.1^{* *}$ \\
Light (L) & $1.7^{\text {ns }}$ & $0.7^{\text {ns }}$ & $1.1^{\text {ns }}$ & $0.2^{\text {ns }}$ & $0.4^{\text {ns }}$ \\
HAS (H) & $0.4^{\text {ns }}$ & $0.4^{\text {ns }}$ & $3.1^{\text {ns }}$ & $0.7^{\text {ns }}$ & $0.3^{\text {ns }}$ \\
G $\times$ L & $1.5^{\text {ns }}$ & $0.3^{\text {ns }}$ & $0.3^{\text {ns }}$ & $0.8^{\text {ns }}$ & $0.3^{\text {ns }}$ \\
G $\times$ H & $0.6^{\text {ns }}$ & $0.8^{\text {ns }}$ & $0.5^{\text {ns }}$ & $0.6^{\text {ns }}$ & $0.6^{\text {ns }}$ \\
L $\times$ H & $1.6^{\text {ns }}$ & $0.1^{\text {ns }}$ & $0.3^{\text {ns }}$ & $0.1^{\text {ns }}$ & $0.3^{\text {ns }}$ \\
G $\times$ L $\times$ H & $1.1^{\text {ns }}$ & $0.3^{\text {ns }}$ & $0.3^{\text {ns }}$ & $0.9^{\text {ns }}$ & $0.5^{\text {ns }}$ \\
\hline
\end{tabular}

$* * *$ : significant at the $1 \%$ and $5 \%$ probability levels, respectively; ns: not significant.

were significant for all the traits, except the double interaction tissue $\times$ light in the case of total tocopherol content. Based on the magnitude of $F$ values, the type of tissue (cotyledon or radicle) was the main factor influencing plastochromanol-8, total tocopherol content and the concentrations of $\beta$ - and $\delta$-tocopherol, whereas the concentrations of $\alpha$ - and $\gamma$-tocopherol were mainly influenced by the genotype. Light effects were, in general, of low magnitude (Table 3).

\section{Changes in plastochromanol-8 content during germination and seedling growth}

The changes in plastochromanol-8 content during imbibition differed greatly between cotyledons and radicles (compare Fig. 1A, B with Fig. 1C, D). In cotyledons, plastochromanol-8 content increased after 48 (light) or 60 (darkness) HAS (Fig. 1). The cotyledons of line BCT-4, selected for increased $\gamma$-tocopherol content, showed a markedly higher accumulation of plastochromanol-8 than the other lines, particularly from 48 HAS onwards. This is in contrast to the other lines that were also selected for increased $\gamma$-tocopherol content (BCT-2 and BCT-5). Cotyledons of BCT-5 showed the lowest plastochromanol-8 content (Fig. 1A, B). In the radicles, plastochromanol-8 content remained almost constant during imbibition until 36 HAS under light conditions, after which they decreased sharply to values close to zero (Fig. 1C). Under dark conditions, plastochromanol-8 content increased at 36 HAS in the radicles of some lines, decreasing sharply to values close to zero (Fig. 1D), as also observed under light conditions.

\section{Changes in total tocopherol content during germination and seedling growth}

Total tocopherol contents changed only slightly in cotyledons during imbibition, with a small increase for most lines between 60 and 70 HAS (Fig. 2A and B). It is noteworthy that the line with low tocopherol content in seeds, BCT-3, maintained a reduced tocopherol content in the cotyledons during the whole sampling period. A much higher standard error of the means was observed at 120 HAS under dark conditions, which probably corresponds to initial tissue deterioration under dark conditions. In the radicles, the pattern of total tocopherol was different from the

Table 3. Analysis of variance ( $F$ values) for plastochromanol-8 (Plasto-8) content [mg $\left.(\mathrm{kg} \text { dry tissue })^{-1}\right]$, total tocopherol $(\mathrm{T})$ content $\left[\mathrm{mg}(\mathrm{kg} \text { dry tissue })^{-1}\right.$ ] and concentration of individual tocopherols (\% total tocopherols) in cotyledons and roots of eight Ethiopian mustard lines during germination under light and dark conditions from 12 to $120 \mathrm{~h}$ after sowing (HAS)

\begin{tabular}{lrrrrrr}
\hline Source of variation & Plasto-8 & Total-T & $\alpha-\mathrm{T}$ & $\beta-\mathrm{T}$ & $\gamma-\mathrm{T}$ & $\delta$-T \\
\hline Genotype (G) & $203.9^{* *}$ & $349.5^{* *}$ & $3924.3^{* *}$ & $250.1^{* *}$ & $8137.6^{* *}$ & $18.1^{* *}$ \\
Tissue (T) & $6176.6^{* *}$ & $9989.4^{* *}$ & $195.8^{* *}$ & $936.0^{* *}$ & $12.3^{* *}$ & $366.9^{* *}$ \\
Light (L) & $69.2^{* *}$ & $0.1^{\text {ns }}$ & $99.1^{* *}$ & $29.8^{* *}$ & $91.2^{* *}$ & $14.9^{* *}$ \\
HAS (H) & $47.6^{* *}$ & $161.3^{* *}$ & $1666.8^{* *}$ & $383.9^{* *}$ & $4065.9^{* *}$ & $90.4^{* *}$ \\
G $\times \mathrm{T}$ & $122.8^{* *}$ & $164.8^{* *}$ & $146.4^{* *}$ & $22.0^{* *}$ & $274.4^{* *}$ & $28.3^{* *}$ \\
G $\times \mathrm{L}$ & $3.1^{* *}$ & $4.2^{* *}$ & $18.4^{* *}$ & $6.8^{* *}$ & $23.1^{* *}$ & $2.7^{* *}$ \\
$\mathrm{G} \times \mathrm{H}$ & $9.4^{* *}$ & $9.5^{* *}$ & $97.2^{* *}$ & $17.2^{* *}$ & $185.1^{* *}$ & $11.9^{* *}$ \\
$\mathrm{~T} \times \mathrm{L}$ & $128.7^{* *}$ & $1.2^{\text {ns }}$ & $65.6^{* *}$ & $182.1^{* *}$ & $29.3^{* *}$ & $12.7^{* *}$ \\
$\mathrm{~T} \times \mathrm{H}$ & $489.5^{* *}$ & $486.4^{* *}$ & $128.3^{* *}$ & $74.1^{* *}$ & $165.1^{* *}$ & $130.0^{* *}$ \\
$\mathrm{~L} \times \mathrm{H}$ & $16.0^{* *}$ & $3.9^{* *}$ & $17.4^{* *}$ & $4.8^{* *}$ & $24.4^{* *}$ & $7.0^{* *}$ \\
$\mathrm{G} \times \mathrm{T} \times \mathrm{L}$ & $1.6^{\mathrm{ns}}$ & $4.2^{* *}$ & $5.2^{* *}$ & $10.1^{* *}$ & $3.6^{* *}$ & $2.7^{* *}$ \\
$\mathrm{G} \times \mathrm{T} \times \mathrm{H}$ & $7.7^{* *}$ & $8.3^{* *}$ & $15.7^{* *}$ & $5.6^{* *}$ & $23.7^{* *}$ & $11.8^{* *}$ \\
$\mathrm{G} \times \mathrm{L} \times \mathrm{H}$ & $2.5^{* *}$ & $2.0^{* *}$ & $5.8^{* *}$ & $3.1^{* *}$ & $9.8^{* *}$ & $1.9^{* *}$ \\
$\mathrm{~T} \times \mathrm{L} \times \mathrm{H}$ & $27.7^{* *}$ & $3.5^{* *}$ & $7.2^{* *}$ & $10.4^{* *}$ & $3.6^{* *}$ & $7.1^{* *}$ \\
$\mathrm{G} \times \mathrm{T} \times \mathrm{L} \times \mathrm{H}$ & $1.4^{* *}$ & $1.5^{*}$ & $2.3^{* *}$ & $2.4^{* *}$ & $3.4^{* *}$ & $1.9^{* *}$ \\
\hline
\end{tabular}

**, $*$ : significant at the $1 \%$ and $5 \%$ probability levels, respectively; ns: not significant. 

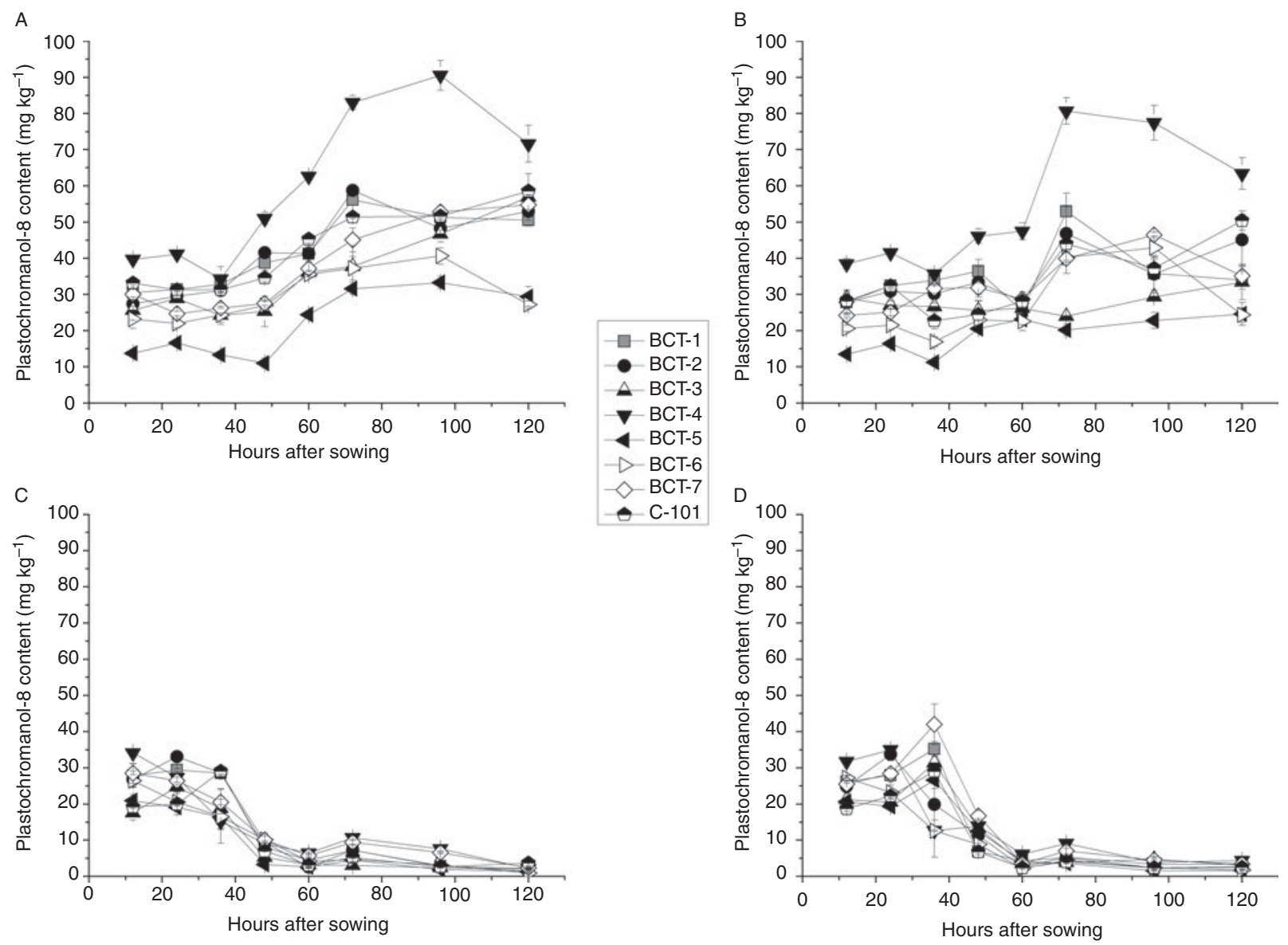

Figure 1. Plastochromanol- 8 content $\left[\mathrm{mg}(\mathrm{kg} \text { dry tissue })^{-1}\right]$ in cotyledons and radicles of Ethiopian mustard lines BCT-1 through BCT-7, with contrasting tocopherol levels, and control line C-101, during germination under light and dark conditions. (A) Cotyledon, light; (B) cotyledon, darkness; (C) radicle, light; (D) radicle, darkness. Data points and error bars represent mean \pm standard error of three replications.

cotyledons, reducing drastically between 24 and 36 HAS in most of the lines, though in some cases the reduction was less pronounced under dark conditions (Fig. 2).

\section{Changes in $\alpha$-tocopherol and $\gamma$-tocopherol profiles during germination and seedling growth}

Changes in the concentrations of $\alpha$-tocopherol and $\gamma$-tocopherol during imbibition are shown in Fig. 3 and Fig. 4, respectively. Three different patterns were observed in relation to changes in the tocopherol profile in the cotyledons as well as the radicles.

The first pattern was found in lines selected for a high relative concentration of $\alpha$-tocopherol (BCT-3, BCT-6 and BCT-7) and those in which no selection for tocopherol profile was made (BCT-1 and control line C-101), showing an increase in $\alpha$-tocopherol and concomitant reduction in $\gamma$-tocopherol concentration between 24 and 60 HAS, decreasing slightly earlier in radicles than cotyledons (Figs 3A, B and 4A, B).
Over 95\% $\alpha$-tocopherol levels were reached from 60 HAS onwards, both under light and dark conditions (Fig. 3). In contrast, $\gamma$-tocopherol levels decreased from around $30-50 \%$ to $<5 \%$ between 12 and 60 HAS.

A second pattern was observed for lines BCT-2 and BCT-5, selected for high relative concentration of $\gamma$-tocopherol in seeds. In these lines, $\alpha$-tocopherol in cotyledons increased drastically from $>20 \%$ of total tocopherols at 12 HAS to a final level around 90\% at 120 HAS (Fig. 3). The biggest increase occurred between 24 and 72 HAS, and slightly earlier in radicles than in cotyledons.

Finally, line BCT-4, also selected for high $\gamma$-tocopherol in seeds, showed a completely different pattern to the other lines, with $\alpha$-tocopherol showing a moderate increase to final values of $33.9 \%$ (light) and $22.5 \%$ (darkness) (Fig. 3) and $\gamma$-tocopherol showing only a slight reduction to final values of $61.4 \%$ (light) and $72.5 \%$ (darkness) (Fig. 4). The radicles of line BCT-4 showed a similar pattern to that observed in the cotyledons, maintaining a high relative concentration of $\gamma$-tocopherol throughout the whole sampling 

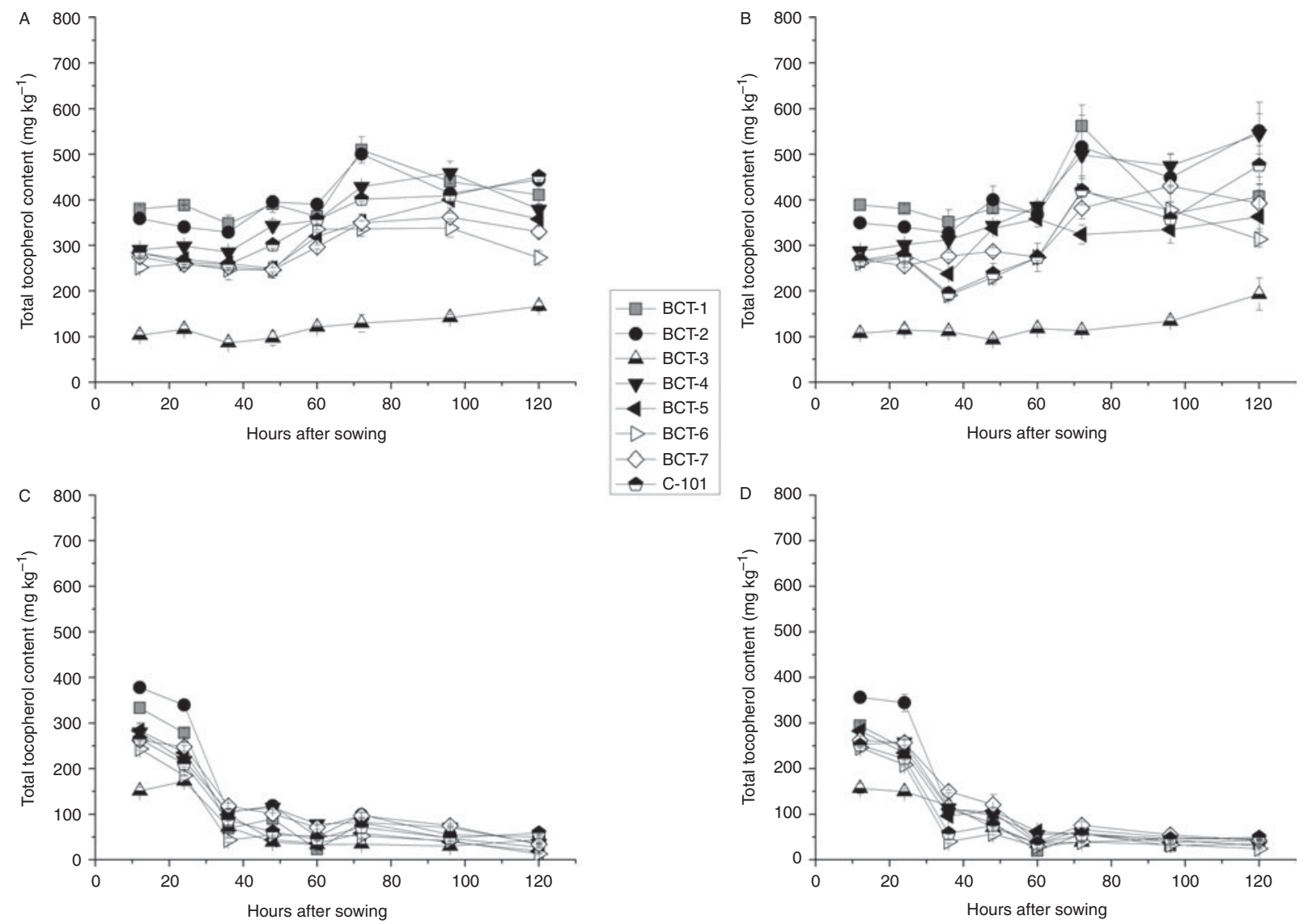

Figure 2. Total tocopherol content [mg $(\mathrm{kg} \text { dry tissue })^{-1}$ ] in cotyledons and radicles of Ethiopian mustard lines BCT-1 through BCT-7, with contrasting tocopherol levels, and control line C-101, during germination under light and dark conditions. (A) Cotyledon, light; (B) cotyledon, darkness; (C) radicle, light; (D) radicle, darkness. Data points and error bars represent mean \pm standard error of three replications.

period to reach a relative concentration of $83.5 \%$ (light) and $80.3 \%$ (darkness) at 120 HAS (Fig. 4).

\section{Tocopherol profile in the leaves of selected lines}

The observation that cotyledons and radicles of line BCT-4 maintained much higher $\gamma$-tocopherol content than the other lines, even at 120 HAS, suggested that the high $\gamma$-tocopherol trait might also be present in plant parts other than seeds/seedlings. This was further investigated by analysing the tocopherol profile in leaves from adult plants $(94 \mathrm{~d}$ after planting) of the three lines with a high $\gamma$-tocopherol content in seeds and the control line C-101. The latter had an average leaf tocopherol profile made up of $93.9 \pm 0.6 \%$ (mean \pm standard error) $\alpha$-tocopherol, $2.8 \pm 0.2 \% \beta$-tocopherol, $1.6 \pm 0.1 \% \gamma$-tocopherol and $1.7 \pm 0.2 \% \delta$-tocopherol. Line BCT-2 had $90.3 \pm 0.6 \%$ $\alpha$-tocopherol, $3.1 \pm 0.2 \% \quad \beta$-tocopherol, $5.0 \pm 0.2 \%$ $\gamma$-tocopherol and $1.6 \pm 0.2 \% \delta$-tocopherol in leaves. Leaf tocopherol profile in BCT-5 was $90.9 \pm 0.5 \%$ $\alpha$-tocopherol, $3.3 \pm 0.2 \% \quad \beta$-tocopherol, $4.5 \pm 0.3 \%$ $\gamma$-tocopherol and $1.3 \pm 0.2 \% \delta$-tocopherol. However, line BCT-4 had a markedly different leaf tocopherol profile made up of $23.5 \pm 1.2 \% \quad \alpha$-tocopherol, $72.9 \pm 1.1 \% \gamma$-tocopherol and $3.6 \pm 0.4 \% \delta$-tocopherol, with no $\beta$-tocopherol being detected. This confirmed that the high $\gamma$-tocopherol trait in BCT-4 is not only expressed in the seeds, but also in other plant parts such as leaves.

\section{Factors influencing germination and seedling growth}

The analysis of variance indicated significant differences between genotypes for cotyledon and radicle weight during germination and early stages of seedling growth. However, no significant differences between genotypes were observed for germination percentage (Table 4; Fig. 5). Light conditions significantly influenced the three traits. None of the interactions were significant for germination percentage, but all of them were significant for cotyledon and radicle weight (Table 4). Final germination percentage was slightly higher under dark conditions (98.1\%) than under light conditions (97.8\%). Changes in cotyledon 


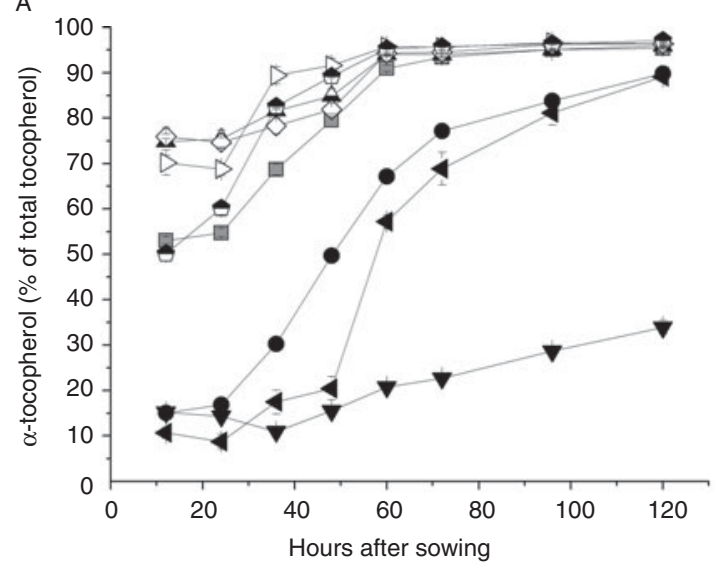

C

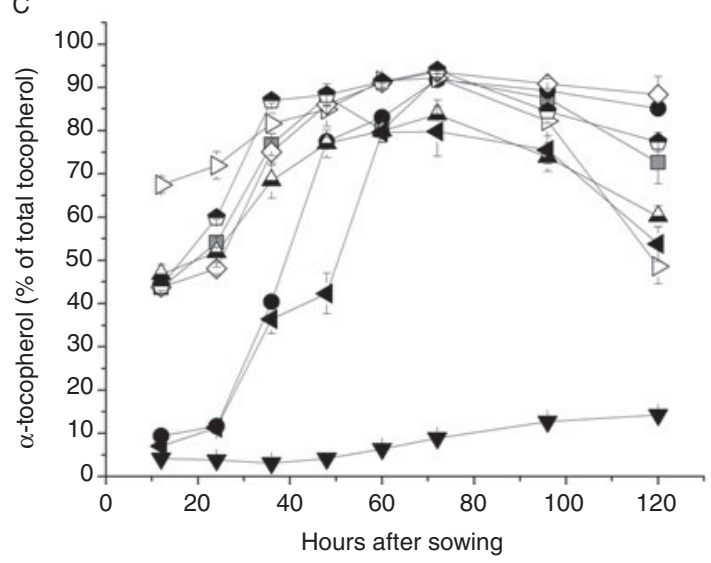

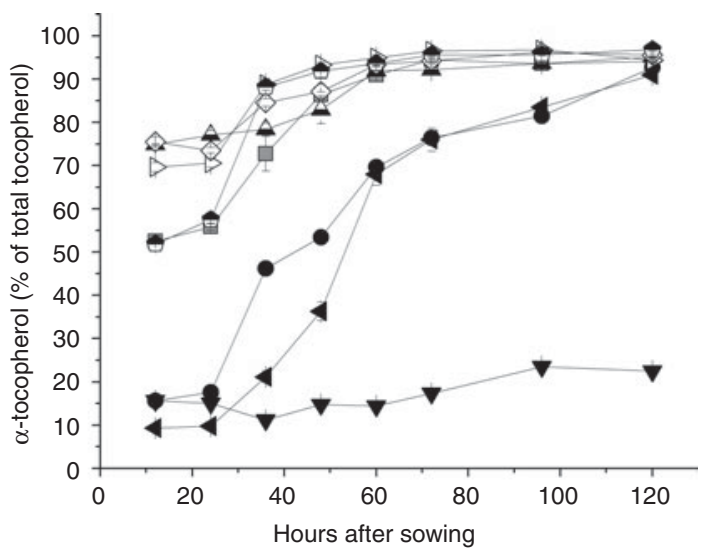

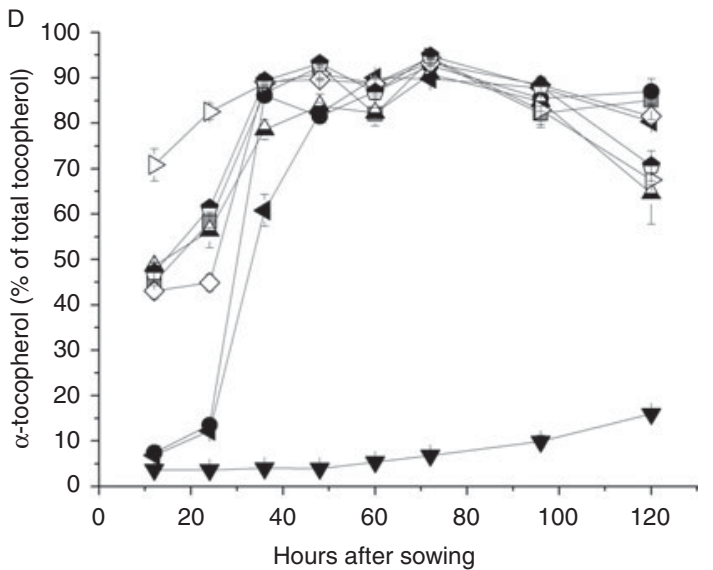

Figure 3. $\alpha$-Tocopherol content (\% total tocopherols) in cotyledons and radicles of Ethiopian mustard lines BCT-1 through BCT-7, with contrasting tocopherol levels, and control line C-101, during germination under light and dark conditions. (A) Cotyledon, light; (B) cotyledon, darkness; (C) radicle, light; (D) radicle, darkness. Data points and error bars represent mean \pm standard error of three replications.

and radicle weights during germination are shown in Fig. 6 . The three lines with high relative concentration of $\gamma$-tocopherol in seeds (BCT-2, BCT-4 and BCT-5) showed the lowest cotyledon weight throughout the whole sampling period, both under light (Fig. 6A) and dark conditions (Fig. 6B), while the line BCT-6, with high relative concentration of $\alpha$-tocopherol, showed the highest cotyledon weight under both light treatments. However, the lines showed also marked differences for seed size, with high $\gamma$-tocopherol lines having lower thousand-seed weight than the other lines (Table 1). Correlation coefficients between thousand-seed weight and mean cotyledon weight at 120 HAS were $0.93(P<0.01)$ under light conditions and $0.74(P<0.01)$ under dark conditions. At the radicle level, two lines with high relative concentration of $\alpha$-tocopherol in seeds (BCT- 6 and BCT-7) showed higher radicle weight at 120 HAS under light conditions than the other lines (Fig. 6C). Under dark conditions, lines BCT-3, with low total tocopherol content, and BCT-5, with high relative concentration of $\gamma$-tocopherol, showed markedly lower radicle weight at 120 HAS (Fig. 6D). Examination of correlation coefficients between thousand-seed weight and radicle weight at $120 \mathrm{HAS}$ also indicated that both traits were highly correlated both under light $(r=0.94 ; P<0.01)$ and dark conditions $(r=0.90 ; P<0.01)$. It is noteworthy that the high $\gamma$-tocopherol line BCT-4, which maintained high $\gamma$-tocopherol content in cotyledons and radicles throughout the whole sampling period, showed a similar growth pattern to the other two high $\gamma$-tocopherol lines in which $\gamma$-tocopherol was nearly completely replaced by $\alpha$-tocopherol during germination (BCT-2 and BCT-5), except in the case of radicles of BCT-5 under dark conditions, which showed markedly lower weight (Fig. 6D).

The loss of dry weight of cotyledons and subsequent increase of dry weight of radicles during seedling growth was more pronounced under dark conditions. Thus, the average cotyledon weight of the eight lines at 120 HAS was $13.1 \mathrm{~g}$ under light conditions, compared to $10.1 \mathrm{~g}$ under dark conditions $(t=9.5, P<0.01)$, whereas the average radicle weight at the same sampling time was $8.3 \mathrm{~g}$ under light 
A

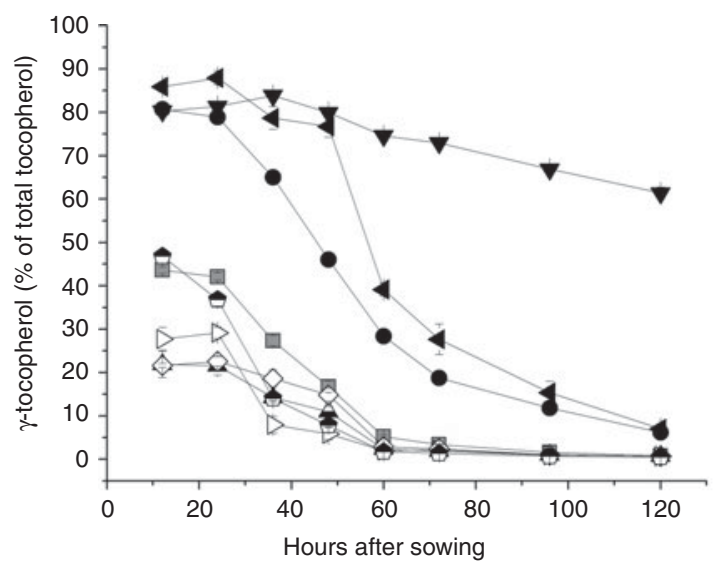

C

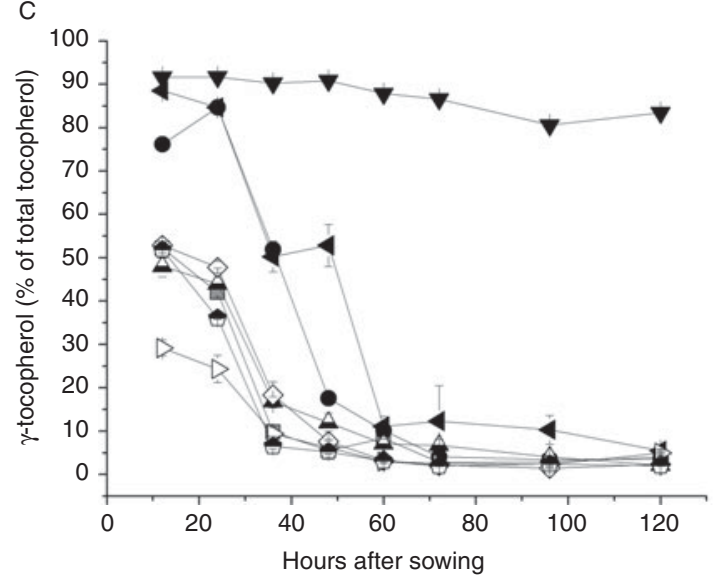

B

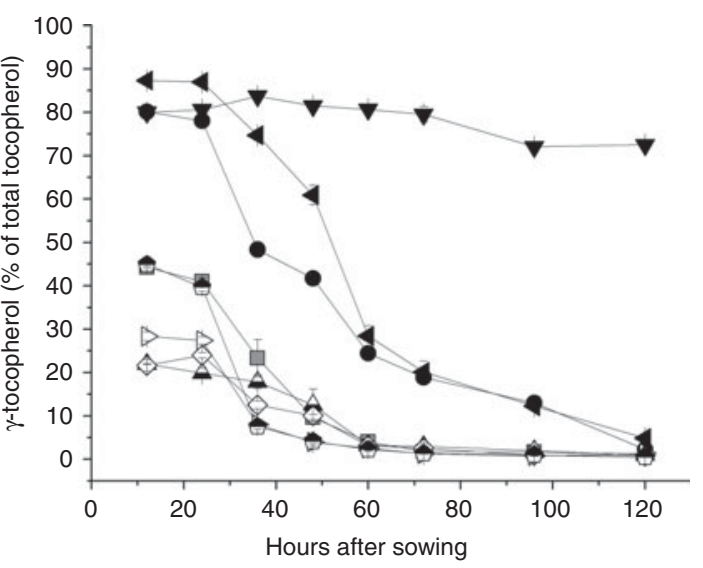

D

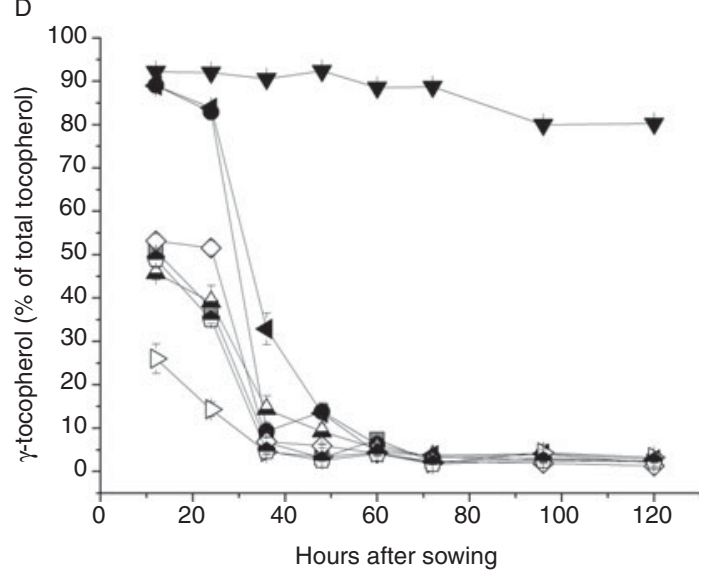

Figure 4. $\gamma$-Tocopherol content (\% total tocopherols) in cotyledons and radicles of Ethiopian mustard lines BCT-1 through BCT-7, with contrasting tocopherol levels, and control line C-101, during germination under light and dark conditions. (A) Cotyledon, light; (B) cotyledon, darkness; (C) radicle, light; (D) radicle, darkness. Data points and error bars represent mean \pm standard error of three replications.

conditions, compared to $9.4 \mathrm{~g}$ under dark conditions $(t=4.4, P<0.01)$.

\section{Discussion}

The major change observed in cotyledons and radicles of Ethiopian mustard lines during germination was a decrease in $\gamma$-tocopherol that was offset by an increase in $\alpha$-tocopherol in most of the lines, with the exception of BCT- 4 which exhibited high $\gamma$-tocopherol content in cotyledons and radicles during the whole sampling period. Studies in other species of the Brassicaceae have shown different patterns of tocopherol mobilization during germination. In rapeseed seedlings, Zhang et al. (2007) reported a marked reduction of $\gamma$-tocopherol content during seed germination, both under light and dark conditions, which was paralleled by a concomitant increase of $\alpha$-tocopherol. The results are in agreement with the results found in the present research for most of the Ethiopian mustard lines. However, Zielinski and Kozlowska (2003) found a different pattern in the same species, in which $\gamma$-tocopherol reached a maximum between 2 (light) and 4 (darkness) days after sowing (DAS) and then decreased. A similar pattern was observed in the

Table 4. Analyses of variance ( $F$ values) for germination percentage and average cotyledon and radicle weights per seedling (mg dry tissue) in eight Ethiopian mustard lines during germination under light and dark conditions from 12 to $120 \mathrm{~h}$ after sowing (HAS)

\begin{tabular}{lccr}
\hline $\begin{array}{l}\text { Source of } \\
\text { variation }\end{array}$ & $\begin{array}{c}\text { Germination } \\
\text { percentage }\end{array}$ & $\begin{array}{c}\text { Cotyledon } \\
\text { weight }\end{array}$ & $\begin{array}{r}\text { Radicle } \\
\text { weight }\end{array}$ \\
\hline Genotype (G) & $1.1^{\text {ns }}$ & $394.7^{* *}$ & $137.3^{* *}$ \\
Light (L) & $7.3^{* *}$ & $86.9^{* *}$ & $569.6^{* *}$ \\
HAS (H) & $1514.1^{* *}$ & $180.6^{* *}$ & $1393.1^{* *}$ \\
G $\times$ L & $1.8^{\text {ns }}$ & $2.4^{* *}$ & $7.4^{* *}$ \\
G $\times$ H & $0.2^{\text {ns }}$ & $3.6^{* *}$ & $8.9^{* *}$ \\
L $\times$ H & $0.2^{\text {ns }}$ & $9.4^{* *}$ & $23.0^{* *}$ \\
G $\times$ L $\times \mathrm{H}$ & $0.4^{\text {ns }}$ & $1.6^{* *}$ & $2.3^{* *}$ \\
\hline
\end{tabular}

$* *, *$ : significant at the $1 \%$ and $5 \%$ probability levels, respectively; ns: not significant. 

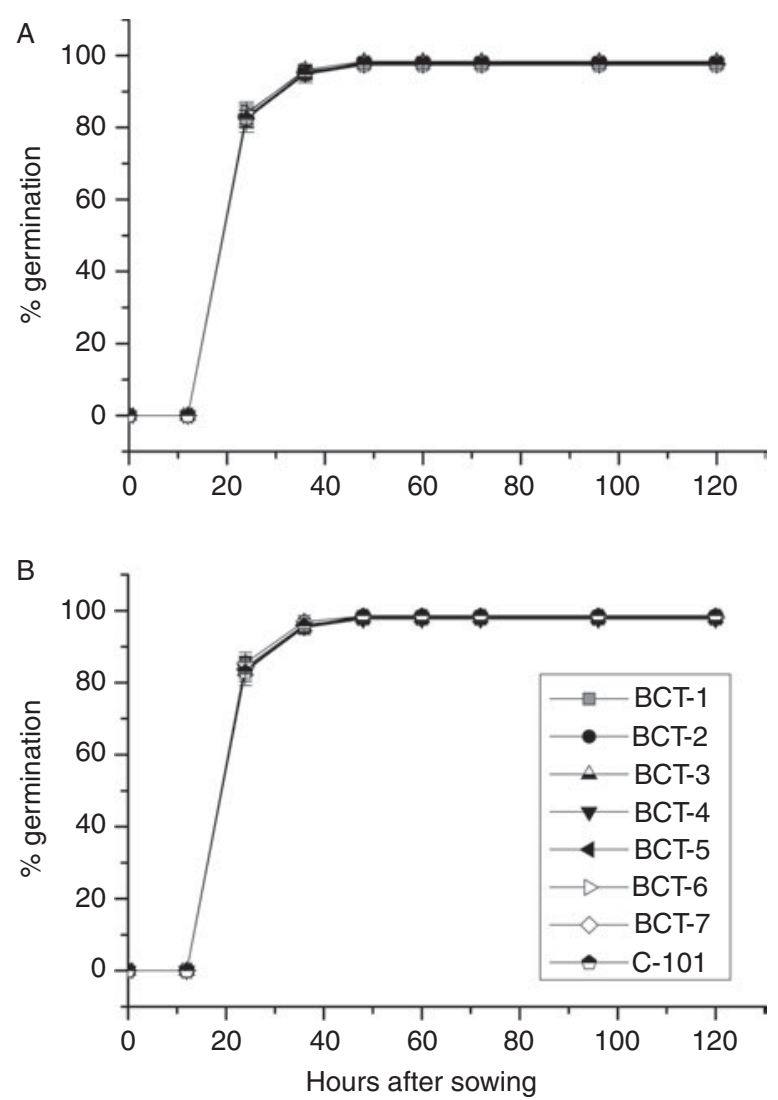

Figure 5. Average germination percentage in Ethiopian mustard lines BCT-1 through BCT-7, with contrasting levels of tocopherols, and control line C-101, during germination under light and dark conditions. (A) Light; (B) darkness. Data points and error bars represent mean \pm standard error of four replications.

same study for radish (Raphanus sativus L.) seedlings. Conversely, $\gamma$-tocopherol showed a constant decrease in white mustard (Sinapis alba L.), more marked under dark conditions (Zielinski and Kozlowska, 2003). In legumes, Fernández-Orozco et al. (2008) reported clear differences between species. In mung bean [Vigna radiata (L.) R. Wilczek] seeds, $\alpha$-tocopherol content increased and $\gamma$-tocopherol content decreased gradually during germination, whereas in soybean [Glycine $\max (\mathrm{L}$.) Merr.] both tocopherol forms increased to reach a maximum between 3 and 5 DAS and then decreased. Similar results for soybean were reported by Shi et al. (2010). It can be concluded from the above discussion that tocopherol changes during germination depend, to a large extent, on the species under study. The present research also showed marked differences in the tocopherol mobilization pattern in lines of the same species, as was the case of line BCT- 4 .

Some differences between light and dark conditions were observed. Radicle length was promoted under dark conditions, which is in agreement with previous studies in Brassica spp. (Fallah-Tossi and Baki, 2013). In relation to tocopherols, Zhang et al.
(2007) reported that the reduction of $\gamma$-tocopherol and the concomitant increase of $\alpha$-tocopherol during germination of rapeseed seeds occurred more rapidly under dark conditions. We have not observed such an effect. On the contrary, $\alpha$-tocopherol accumulation was delayed in the radicles of some lines under dark conditions, whereas no consistent differences were observed in the cotyledons. Zielinski and Kozlowska (2003) also observed differences associated with the presence or absence of light in the accumulation pattern of both tocopherol forms during germination of several Brassicacea species, though such differences were in different directions depending on the species. Thus, darkness promoted the accumulation of $\gamma$-tocopherol in radish and rapeseed seedlings, whereas this tocopherol form was present in higher concentration in the presence of light in white mustard.

Line BCT-4 showed consistently a much greater relative concentration of $\gamma$-tocopherol in cotyledons and radicles than the other lines, both under light and dark conditions. This line also showed higher plastochromanol-8 content in the cotyledons. Analysis of leaves confirmed that the high $\gamma$-tocopherol content was also predominant in vegetative tissue of adult plants. In the plant kingdom, $\alpha$-tocopherol is the predominant tocopherol derivative in most plant tissues, except in dicot seeds, fruits and tubers, where $\gamma$-tocopherol is the predominant form. Cereal seeds mainly contain tocotrienols (Horvath et al., 2006). In particular, photosynthetic tissues almost universally contain large proportions of $\alpha$-tocopherol (DellaPenna and Pogson, 2006). Exceptions in naturally occurring plants are very scarce, for example in lettuce and spinach, which contain higher proportions of $\gamma$-tocopherol in leaves (Szymańska and Kruk, 2008). There are also several examples in which modified tocopherol profiles have been obtained in mutant and transgenic lines of plants, with the modified tocopherol profiles being expressed both in seeds and leaves, for example in Arabidopsis (Cheng et al., 2003; Bergmüller et al., 2003; Kanwischer et al., 2005; MèneSaffrané et al., 2010), tobacco (Nicotiana tabacum L.; Abbasi et al., 2007) and sunflower (Helianthus annuus L.; Del Moral et al., 2012). Line BCT-4 was selected for its low $\alpha-/ \gamma$-tocopherol ratio in seeds in the course of a conventional breeding programme in which two other lines with similarly low $\alpha-/ \gamma$-tocopherol ratio in seeds, BCT-2 and BCT-5, were developed (Velasco et al., 2013). Lines BCT-2 and BCT-5 were also included in the present research and, though they showed differences in the accumulation pattern of $\alpha$ - and $\gamma$-tocopherol during germination, their relative concentrations of $\alpha$-tocopherol in cotyledons and radicles at 120 HAS, as well as in leaves, was similar to those of the control. The relative concentration of $\alpha$ - and $\gamma$-tocopherol in plant tissues is controlled by $\gamma$-tocopherol methyltransferase $(\gamma$-TMT), which adds 

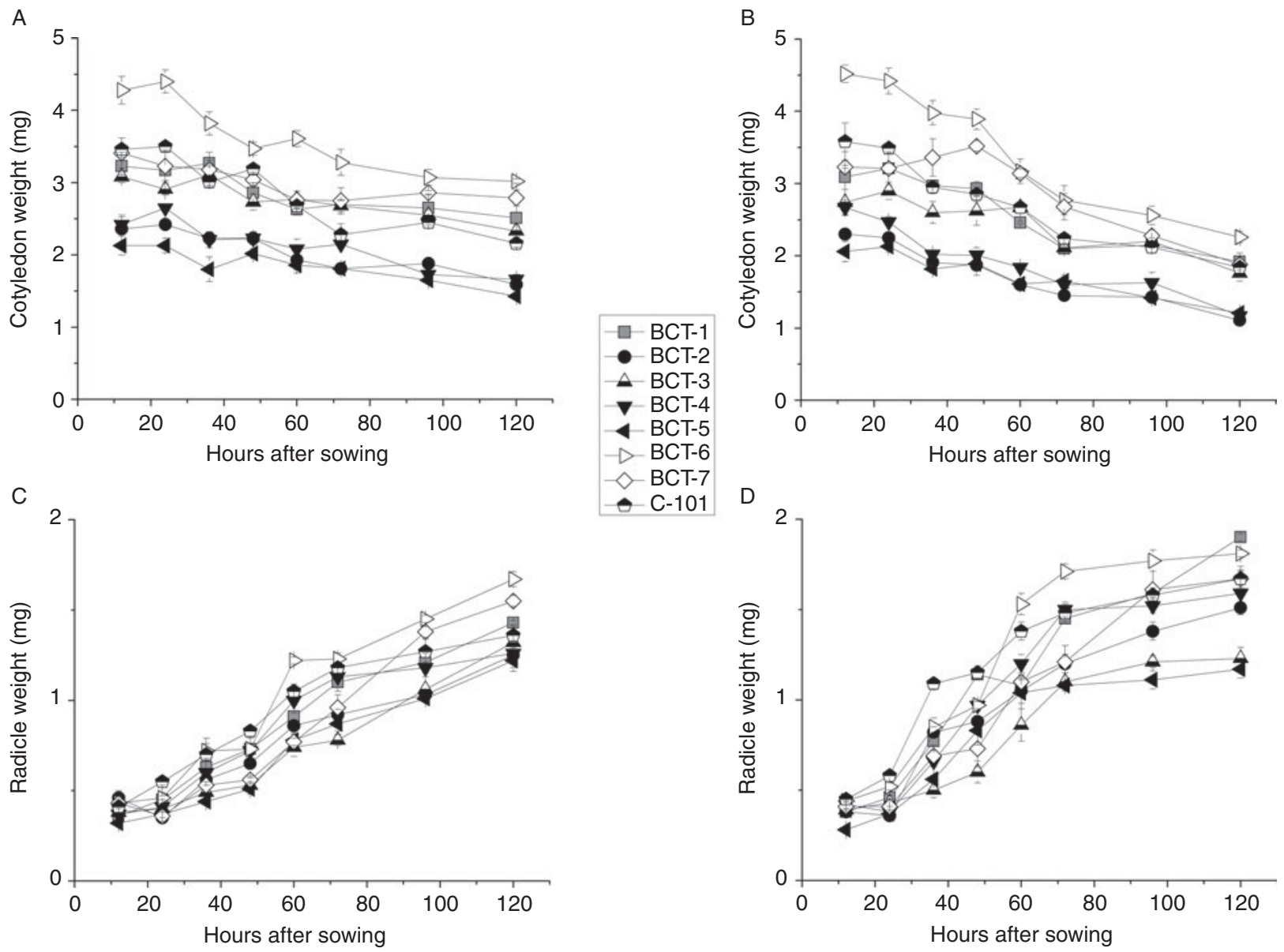

Figure 6. Average cotyledon and radicle weight per seedling (mg dry tissue) in Ethiopian mustard lines BCT-1 through BCT-7, with contrasting levels of tocopherols, and control line C-101, during germination under light and dark conditions. (A) Cotyledon, light; (B) cotyledon, darkness; (C) radicle, light; (D) radicle, darkness. Data points and error bars represent mean \pm standard error of three replications.

a methyl group at the $\mathrm{C} 5$ position of the chromanol ring of $\gamma$-tocopherol, yielding $\alpha$-tocopherol (MèneSaffrané and DellaPenna, 2010). The study of the inheritance of low $\alpha-/ \gamma$-tocopherol ratio in BCT-4 revealed that the trait is controlled by a single gene, which was hypothesized to be a $\gamma$-TMT locus (Velasco et al., 2013). The mutation resulting in high $\gamma$-tocopherol accumulation in BCT-4 is expressed in plant tissues other than seeds, whereas those in BCT-2 and BCT-5 are seed-specific, which suggests genetic differences between BCT-4 and both BCT-2 and BCT-5. In sunflower, two lines with increased levels of $\gamma$-tocopherol in seeds also showed expression of increased $\gamma$-tocopherol levels in other plant tissues, such as roots, leaves and pollen (Del Moral et al., 2012). Similarly, Arabidopsis mutants carrying a functional null mutation of the gene encoding for the $\gamma$-TMT showed a drastic reduction of $\alpha$-tocopherol and a concomitant increase of $\gamma$-tocopherol in leaves (Bergmüller et al., 2003). A similar effect was observed in $\gamma$-TMT-silenced plants of tobacco
(Abbasi et al., 2007). Further research is required to elucidate the genetic basis of differential spatial expression of mutations in Ethiopian mustard lines with similarly increased $\gamma$-tocopherol levels in seeds.

Plastochromanol-8 and tocopherols play an important role in protecting seeds from oxidative damage, and subsequently in increasing seed longevity (Sattler et al., 2004; Mène-Saffrané et al., 2010). During seed germination and early seedling growth, they contribute to minimizing non-enzymatic oxidation of polyunsaturated fatty acids (DellaPenna and MèneSaffrané, 2011). Research conducted in Arabidopsis using the tocopherol-deficient mutant vte2 demonstrated that the complete lack of tocopherols and their quinone intermediates 2-methyl-6-phytyl-1,4-benzoquinone (MPBQ) and 2,3-dimethyl-6-phytyl-1,4benzoquinone (DMPBQ) promoted seed lipid peroxidation, resulting in severe seedling growth defects during germination (Sattler et al., 2004, 2006). However, this negative effect was not observed in other tocopherol-deficient mutants such as vte1, which 
was explained on the basis of the accumulation of high levels of DMPBQ, apparently capable of protecting polyunsaturated fatty acids from non-enzymatic lipid oxidation in the absence of tocopherols (Sattler et al., 2004, 2006). In this study, we have not detected any association of total tocopherol content in the seeds with seed germination and seedling growth. Moreover, despite observation of some apparent association between tocopherol profile and seedling growth, such an association was attributed to differences in seed weight between the lines, as suggested by the existence of high correlation coefficients for seed weight with both cotyledon and radicle weights at 120 HAS. Previous studies in Brassica spp. have shown that larger seeds produce more vigorous seedlings, with larger cotyledons and longer roots (Elliot et al., 2008; Singh et al., 2012). In the present research, the three lines with increased $\gamma$-tocopherol content had lower thousand-seed weight than the other lines, while two out of three lines with increased $\alpha$-tocopherol content had higher thousand-seed weight. Additionally, our data suggested that the presence of high levels of $\gamma$-tocopherol instead of $\alpha$ tocopherol in the radicles and cotyledons of line BCT-4 had no influence on seed germination and seedling growth, as seeds of this line showed a germination percentage similar to that of the other lines, and the seedlings exhibited a growth pattern similar to that of other lines with similar seed size. Therefore it is not possible to conclude, with the information available, any influence of the seed tocopherol profile on seedling growth. Further studies specifically designed to disclose the effect of seed weight and seed tocopherol profile on seedling growth would be required.

\section{Financial support}

This work was supported by the Spanish government through Ministerio de Educación y Ciencia and EU FEDER funds, research project AGL2007-62 834/AGR and $\mathrm{PhD}$ student fellowship EBES-2008-003080 to E.G.-N.

\section{Conflicts of interest}

None.

\section{References}

Abbasi, A.R., Hajirezaei, M., Hofius, D., Sonnewald, U. and Voll, L.M. (2007) Specific roles of $\alpha$ - and $\gamma$-tocopherol in abiotic stress responses of transgenic tobacco. Plant Physiology 143, 1720-1738.

Balz, M.K., Schulte, E. and Thier, H.P. (1993) Simultaneous determination of $\alpha$-tocopheryl acetate, tocopherols and tocotrienols by HPLC with flourescence detection in foods. Lipid / Fett 95, 215-220.
Bergmüller, E., Porfirova, S. and Dörmann, P. (2003) Characterization of an Arabidopsis mutant deficient in $\gamma$-tocopherol methyltransferase. Plant Molecular Biology 52, 1181-1190.

Cheng, Z., Sattler, S., Maeda, H., Sakuragi, Y., Bryant, D.A. and DellaPenna, D. (2003) Highly divergent methyltransferases catalyze a conserved reaction in tocopherol and plastoquinone synthesis in cyanobacteria and photosynthetic eukaryotes. Plant Cell 15, 2343-2356.

DellaPenna, D. and Mène-Saffrané, L. (2011) Vitamin E. pp. 179-227 in Rébeillé, F.; Douce, R. (Eds) Advances in Botanical Research, Vol. 59. Biosynthesis of vitamins in plants Part B. Amsterdam, The Netherlands, Elsevier.

DellaPenna, D. and Pogson, B.J. (2006) Vitamin synthesis in plants: tocopherols and carotenoids. Annual Review of Plant Biology 57, 711-738.

Del Moral, L., Fernández-Martínez, J.M., Pérez-Vich, B. and Velasco, L. (2012) Expression of modified tocopherol content and profile in sunflower tissues. Journal of the Science of Food and Agriculture 92, 351-357.

Elliot, R.H., Franke, C. and Rakow, G.F.W. (2008) Effects of seed size and seed weight on seedling establishment, vigour and tolerance of Argentine canola (Brassica napus) to flea beetles, Phyllotreta spp. Canadian Journal of Plant Science 88, 207-217.

Fallah-Tossi, A. and Baki, B.B. (2013) Allometry, growth pattern and seed germination of Brassica juncea (L.) Czern. var. Ensabi influenced by different light and temperature. International Journal of Agriculture and Crop Sciences 5, 2716-2723.

Fernández-Orozco, R., Frias, J., Zielinski, H., Piskula, M.K., Kozlowska, H. and Vidal-Valverde, C. (2008) Kinetic study of the antioxidant compounds and antioxidant capacity during germination of Vigna radiata $\mathrm{cv}$. emmerald, Glycine max cv. jutro and Glycine max cv. merit. Food Chemistry 111, 622-630.

Goffman, F.D., Velasco, L. and Becker, H.C. (1998) Tocopherols contents and other seed quality traits in several Brassica species. pp. 436-438 in Sánchez, J.; Cerdá-Olmedo, E.; Martínez-Force, E. (Eds) Advances in plant lipid research. Seville, Spain, Secretary of Publications of the University of Seville.

Goffman, F.D., Velasco, L. and Thies, W. (1999) Quantitative determination of tocopherols in single seeds of rapeseed (Brassica napus L.). Lipid / Fett 101, 142-145.

Horvath, G., Wessjohann, L., Migirimana, J., Jansen, M. Guisez, Y., Caubergs, R. and Horemans, N. (2006) Differential distribution of tocopherols and tocotrienols in photosynthetic and non-photosynthetic tissues. Phytochemistry 67, 1185-1195.

Kamal-Eldin, A. (2006) Effect of fatty acids and tocopherols on the oxidative stability of vegetable oils. European Journal of Lipid Science and Technology 58, 1051-1061.

Kanwischer, M., Porfirova, S., Bergmüller, E. and Dörmann, P. (2005) Alterations in tocopherol cyclase activity in transgenic and mutant plants of Arabidopsis affect tocopherol content, tocopherol composition, and oxidative stress. Plant Physiology 137, 713-723.

Kumar, D., Yusuf, M.A., Singh, P., Sardar, M. and Sarin, N.B. (2013) Modulation of antioxidant machinery in $\alpha$-tocopherol-enriched transgenic Brassica juncea plants tolerant to abiotic stress conditions. Protoplasma 250, 1079-1089. 
Mène-Saffrané, L. and DellaPenna, D. (2010) Biosynthesis, regulation and functions of tocochromanols in plants. Plant Physiology and Biochemistry 48, 301-309.

Mène-Saffrané, L., Jones, A.D. and DellaPenna, D. (2010) Plastochromanol-8 and tocopherols are essential lipidsoluble antioxidants during seed desiccation and quiescence in Arabidopsis. Proceedings of the National Academy of Sciences USA 107, 17815-17820.

Munné-Bosch, S. (2005) The role of $\alpha$-tocopherol in plant stress tolerance. Journal of Plant Physiology 162, 743-748.

Munné-Bosch, S. and Alegre, L. (2002) The function of tocopherols and tocotrienols in plants. Critical Reviews in Plant Sciences 21, 31-57.

Packer, L. and Obermüller-Jevic, C. (2002) Vitamin E in disease prevention and therapy: future perspectives. pp. 255-288 in Packer, L.; Traber, M.G.; Kraemer, K.; Frei, B. (Eds) The antioxidant vitamins $C$ and $E$. Champaign, Illinois, USA, AOCS Press.

Sattler, S.E., Gilliland, L.U., Magallanes-Lundback, M., Pollard, M. and DellaPenna, D. (2004) Vitamin E is essential for seed longevity and for preventing lipid peroxidation during germination. Plant Cell 16, 1419-1432.

Sattler, S.E., Mène-Saffrané, L., Farmer, E.E., Krischke, M., Mueller, M.J. and DellaPenna, D. (2006) Nonenzymatic lipid peroxidation reprograms gene expression and activates defense markers in Arabidopsis tocopheroldeficient mutants. Plant Cell 18, 3706-3720.
Shi, H., Nam, P.K. and Ma, Y. (2010) Comprehensive profiling of isoflavones, phytosterols, tocopherols, minerals, crude protein, lipid, and sugar during soybean (Glycine max) germination. Journal of Agricultural and Food Chemistry 58, 4970-4976.

Singh, M., Sharma, A., Chauhan, J.S., Meena, R.C., Meena, M.L., Meena, S.S. and Mishra, A.P. (2012) Influence of seed size on germination and early seedling growth in Indian mustard (Brassica juncea L.). Indian Journal of Plant Genetic Resources 25, 257-260.

Szymańska, R. and Kruk, J. (2008) Tocopherol content and isomers' composition in selected plant species. Plant Physiology and Biochemistry 46, 29-33.

Velasco, L. and Goffman, F.D. (2000) Tocopherol, plastochromanol and fatty acid patterns in the genus Linum. Plant Systematics and Evolution 221, 77-88.

Velasco, L., García-Navarro, E., Pérez-Vich, B. and Fernández-Martínez, J.M. (2013) Selection for contrasting tocopherol content and profile in Ethiopian mustard. Plant Breeding 132, 694-700.

Zhang, H., Vasanthan, T. and Wettasinghe, M. (2007) Enrichment of tocopherols and phytosterols in canola oil during seed germination. Journal of Agricultural and Food Chemistry 55, 355-359.

Zielinski, H. and Kozlowska, H. (2003) The content of tocopherols in Cruciferae sprouts. Polish Journal of Food and Nutrition Sciences 53, 25-31. 